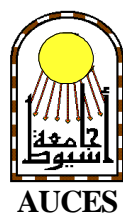

\title{
ENVIRONMENTAL DETERIORATION AND CONSERVATION OF MONUMENTAL BASALT, EGYPT
}

\author{
Badawy Ismail \\ Conservation Dept., Faculty of Art, South Valley Univ., Qena
}

\begin{abstract}
:
Basalt is one of the natural stones used in both buildings and sculptures along the human being history. It is one of the hardest stones, but also records weathering to different extents by environmental conditions. The current study is focused on examining deterioration and conservation of Basalt used in different locations in Egypt. The study has been carried out using field recording and laboratory analysis to asses the aim of this study. It is indicated that Basalt is experiencing weathering and deterioration noted through thin sections and scanning electron microscopic study indicated by rock mineralogical alteration to unstable minerals. The investigations used also $\mathrm{x}$-ray powder diffraction analysis and $\mathrm{x}$-ray Dispersive analysis. Consolidation has been carried out to enhance the durability of this stone to withstand against the impact of the arid and the semi arid climate of Egypt and to evaluate possible protective treatments.
\end{abstract}

\section{INTRODUCTION :}

Volcanic stones, formed at high temperatures, are not chemically stable even at ambient temperatures in the presence of water, which is the principal agent of alteration (Grissom, 1999).

Basalt is a volcanic igenous rock, basic with silica $45-52 \%$, it is chiefly of calcic plagioclase, clinopyroxene and olivine. Phenocrystcrysts of these dark-coloured minerals and the light-colored plagioclase are common. Basalt tends to be dense and massive, but it can also be vesicular.

This stone can be altered by weathering processes to some alternative minerals. Calcic plagioclase, olivine and pyroxene are the most dominant minerals constituting the basalt such minerals are easily weathered as they are formed in conditions variable from these of present day. In the arid and semiarid conditions of Egypt, the physical and mechanical weathering dominate over the chemical weathering consequently cracking and exfoliation are done.

Basalt are widely spread in Egypt especially near Cairo at Abu Rawash and past Giza cross north El-Fayum at Qatrani. Small outcrops are recorded to the northeast and east of Cairo at $\mathrm{Abu}$ Zaabal, on the east bank of the Nile near Gabel- El Teir and on the west bank near- El Bahnasa and Abu Simbel. Only one ancient quarry is known which located at widan El-Faras on Gabel Qatrani north El-Fayum and quarried during the old kingdom in the fourth through sixth Dynasties and perhaps as early as the third Dynasty (Harrel and Brown 1995). It seems likely that basalt outcrops elsewhere would also have been quarried, especially after the old kingdom. Basalt was widely exploited during the old kingdom for pavements in pyramid temples of the Memphite necropolis.

Basalt pavements and occasionally walls are found in the mortuary temples of the following 
kings, Djoser (Third Dynasty), Userkaf (fifth Dynasty) Pepi I (sixth Dynasty) at Saqqara, Neferirkara and Niuserra (fifth Dynasty) at Abu Sir and Khufu (fourth Dynasty) at Giza. Also, extensive use of basalt was made for walls and pavements in Khufu's valley temple and causeway. The stone was firstly used for small vessels, sarcophagi and statues in the late predynastic period and continued to be commonly employed for this purpose untill the sixth Dynasty. It appears that Basalt was seldom used after old kingdom and then mainly for statuary, especially in the late period and GrecoRoman period.

The aim of the present work is to study the deterioration mechanisms of weathered basalt in order to suggest materials for the conservation of Basalt.

\section{Deterioration of monumental Basalt:}

Basalt is affected by several types of deterioration namely granular disintegration, plats, flakes, efflorescence and biological colonization. The influence of environmental factors has played an important role in the deterioration process of Basalt, particularly due to the biodeterioration agents.

At the Ne-wasar-Rah Temple (at Abu-Sir), water is the dominant deterioration agent of basalt, in addition to the diurnal variation temperatures. The areas have an arid desert climate, and in early morning, the relative humidity is very high leading to condensation of water droplets on the surface of the Basalt. The chemical weathering of this stone is due to a dissolution process of the constituent silicate minerals, causing undesirable discoloration of the ferromagnesian minerals. The colour of the basalt on this temple has changed from almost black to pale brownish grey (Helmi, 1990). Two types of the failure might result from temperature changes of insolation, namely exfoliation disintegration of the stone.

At Ptah temple at Memphite, insolation produces thermal flaking and disintegration due to the mineral disintegration. The colour of the basalt is changed and the surface layer was craked and fell into Flakes (Pl.1, Fig.1). In addition fissuring, cracking and porosity of weathered basalt have been increased. Weathering of basalt produces an amount of insoluble material as a result of chemical processes which change ferrous iron to ferric iron of the mineral constituents. This alteration produces cracks and points of weakness which cause disintegration of basalt and its discoloration (PI. 1, Fig. 2).

The change in relative humidity plays an active role in Basalt decomposition. The durability analyses show the effect of groundwater which carry different insoluble salts that are giving rise to salinization of Basalt (Pl.1, Fig. 3). There is a capillary migration of the soluble ions from saline soils in this site. Groundwater assists in the weathering of basaltic minerals leading to the formation of clay minerals. Microcracks in the stone are saturated with water, weakening its structure by enlarging these imperfections. These cracks allow the circulation of groundwater and constitute an inherent source of weakness and a serious defect.

Also, the evaporation of the absorped water and the plate- like minerals become more compact causing strain and distortion of the stone which eventually contributes to its cracking. Environmental impact on the Ptah basalt blocks leads to cracking as a result of the crystallization of salts absorbed into the stones. The most important role of mechanical weathering by salts is that of salt crystal growth from solutions in stone pores and cracks (Arnold, 1990).

Firstly sodium sulphate, sodium nitrate and magnesium sulphate are rapidly decrease in solubility as temperature falls. Secondly, evaporational concentration of solutions when occurs, highly salts produce crystals of large volumes. Thirdly, salt crystallization is common ion effect, whereby the mixing of two different salt 
solutions with the same major cation can cause salt precipitation (Pl.1, Fig. 3). Hydration and dehydration of the crystallized salts also play a role in the stone decomposition as the volume of the salts increases for sodium sulphate crystals. Another possible category of salt weathering processes involves the differential thermal expansion of the salts. Also, salts entrapped in stone pores may have greater expansion coefficients than the stone minerals. (PI.1, Fig. 5) shows that the migration of the salt solution to the surface of the stone is faster than the rate of drying. The liquid passes out the surface and the crystals of the soluble salts deposit there on the top of the external surface resulting in a visible efflorescence form (Pl.1, Fig.3). Thus the action of the chlorid salts that are highly hygroscopic being the first salts which dissolve grains with water condensation, make them pulverize the stone by granular disintegration.

Also, the durinal changes in temperatures and humidity, as well as the adsorption and disadsorption of water in the stone, cause a mechanical strain in the stone provoking the formation of microcracking parallel to the surface which continuously advances towards the surface causing loosening of material by Flaking. These cracks are filled with absorbed water which leads to higher stresses and consequent stone decohesion in weathered basalt. Exfoliations, crustification and planar disjunction observed in the monumental Basalt are likely to be originated from the salt crystallization and physical weathering process.

So, the deteriorations of basaltic monuments are continued by new cracks in the stones and exfoliations from the surface. The formation of tensional and radical cracks by weathering are widened by exfoliation (Pl.1, Fig. 6) Moreover, Deterioration of basalts seems to be originated through microveins in their structure and fragments from the outer parts of monumental basalt which fall down due to its decohesion (Caner., 1985).
Continuous disintegration of basalt have been observed. Cracks are produced in the body of the stones and small pieces have been exfoliated from the surfaces.

\section{MATERIAL AND METHODS :}

\section{Sampling:}

Different weathered basaltic samples taken from the Ne-weser-Rah, Temple at Abu-Sir, Ptah, temple at Memphite and Tell Basta were examined through mineralogical and petrographical analyses using thin section and scanning electron microscopy (SEM) coupled to an EDAX system.

$\mathrm{X}$-ray powder diffraction analysis. The samples were ground in an agate mortar to a fine powder, pressed into the specimen holder, and mounted in a Philips x-ray diffractometer. The X RD traces were recorded using $\mathrm{Cu} K \alpha$ radiation $\left(\mathbf{1 . 5 4 1 8 A}^{\circ}\right)$ with a Ni filter, at $40 \mathrm{kv}$ and $20 \mathrm{~mA}$.

\section{Physical tests :}

Some physical characteristics of the stone were determined namely bulk density, porosity, water absorption and resistance to compression.

\section{Treatment and Artificial weathering:}

Cubic basaltic samples of $3 \mathbf{c m}$ side length were used for all tests carried out, for this study, six conservation products were used:

1-Tegovakon $\mathbf{V}$ (Ethylsilicate in White Spirit).

2-Wacker 290 (Oligomeric organosiloxane in white Spirte).

3-Paraloid B44. A100\% acrylic resin based on Methyl Methacrylate.

4-Wacker OH 100 (Ethyl Silicate in ethanonal). 5-Silester AR Substitute of Wacker $\mathrm{OH}$.

6-Rhodorsil 224. Polymethylsilovane 8\% in white spirite.

Several physical and mechanical characteristics such as bulk density, water 
absorption, porosity and scanning electron observation, were repeated on samples after treatment with the various products.

\section{Plate (1)}

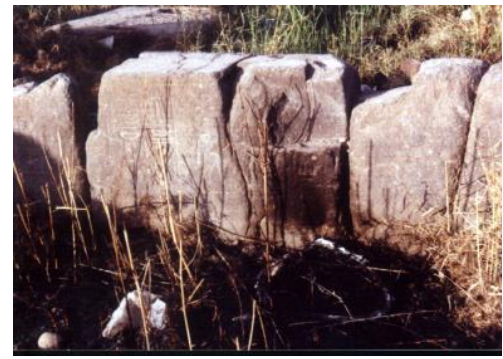

Fig. (1): Basaltic blocks highly cracked due to weathering $\&$ plant vegetation, Memphite

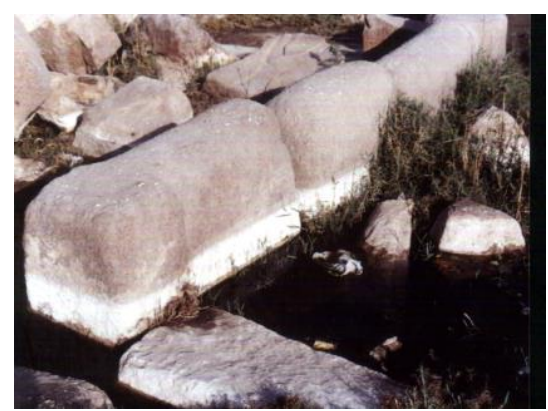

Fig. (3): Field view showing parts of basaltic blocks immerged in domestic water.

Salt efflorescence can be noted

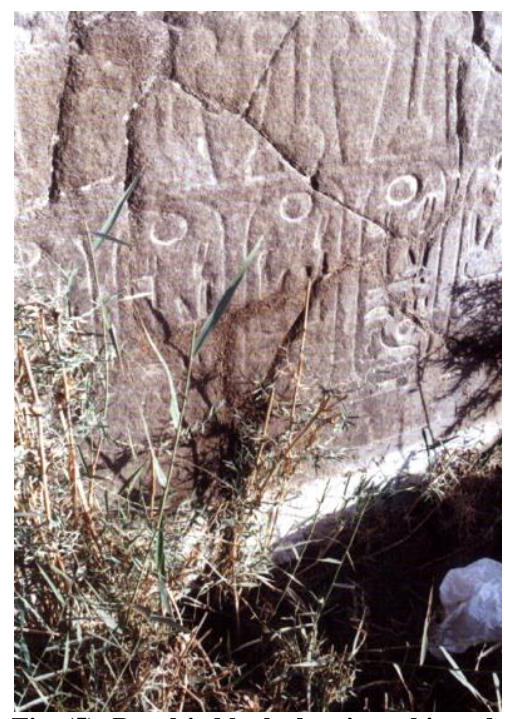

Fig. (5) :Basaltic block showing white salt efflorescence at its base $\&$ coarse single cracks, Memphite.

\section{Accelerated weathering tests:}

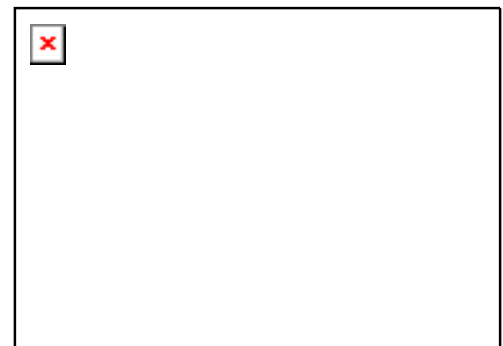

Fig. (2): Dense plant vegetation around Basalt blocks. Cracks are noted due to weathering, Tell Basta
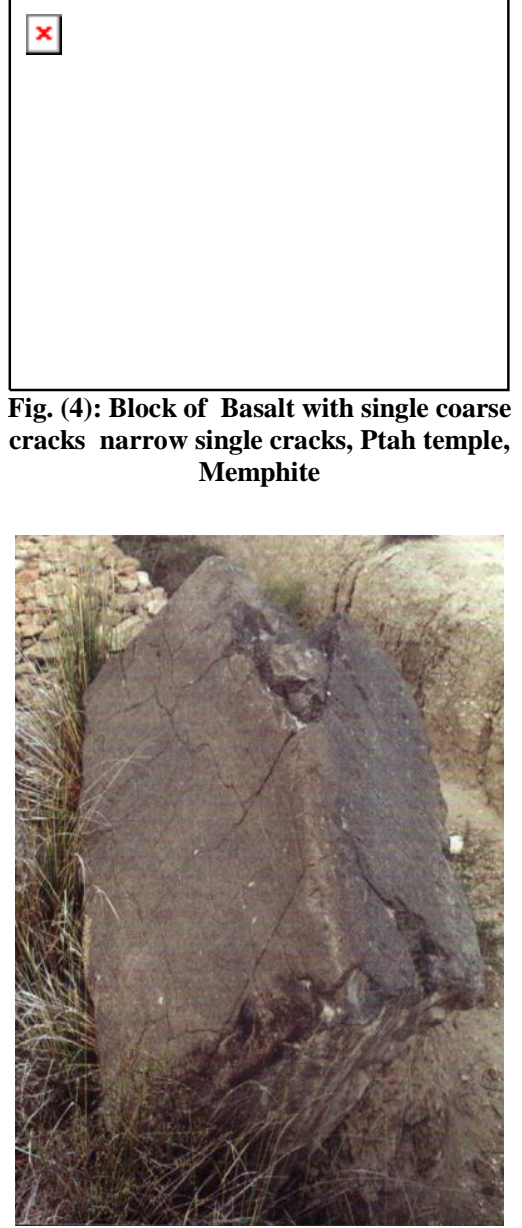

Fig. (6): Parts of basalt show cracking \& severe weathering. Dense plant vegetation indicates new surface water at tell Basta. 
Three accelerated tests were carried out, these test were, salt crystallization test with Sodium chloride, chemical attack with $\mathrm{H}_{2} \mathrm{SO}_{4}$ and wet-dry test.

The salt crystallization tests consisted of 30 cycles of the following $24 \mathrm{~h}$ total immersion in $10 \%$ (w/v) sodium chloride solution, $21 \mathrm{~h}$ drying at $65^{\circ} \mathrm{C}$ and $9 \mathrm{~h}$ for cooling and weighting.

The chemical attack was carried out with $15 \%$ diluted solution of $\mathrm{H}_{2} \mathrm{SO}_{4}$ by 30 cycles. Each cycle consists of $12 \mathrm{~h}$. Total immersion in $15 \% \quad \mathrm{H}_{2} \mathrm{SO}_{4}$ solution is $16 \mathrm{~h}$ drying at $65^{\circ} \mathrm{C}$ and $8 \mathrm{~h}$ drying at air temperature. Basalt samples were subjected to 40 cycles wetting and drying, each cycle consists of complete immersion in distilled water for 24 hours and then drying for 24 hours at $65^{\circ} \mathrm{C}$.

\section{RESULTS:}

\section{Petrography of Monumental Basalt:}

The basaltic stones cotain crystals of plagioclase, fedlspar pyroxene, olivine and opaques (iron oxides).

Plagioclase is partially weathered and replaced by irregularly shaped and distributed patches of secondary clay products along its cleavage planes and fractures, whereas the external more sodic part of the zoned crystal is much less affected by weathering (Pl.2, Fig.2). plagioclase crystal is characterized also by "patchy zoning", and corroded core of (Pl.2, Fig. 3) while the outer zones are more sodic in composition. Inclusions of this sodic phase appear in the corroded core.

Corroded, fractured and twinned plagioclase feldspar crystals are prismatic with "T-shaped" intergrowth (PI.2., Fig. 4). The internal border of the rim is highly irregular and the products of weathering irregularly penetrate the residual core along digitating and tranching fissures.
Olivine crystals exhibit an irregular with sinuous outline colorless in polarized light changed to bright green in crossed nicoles. There is an extensive network of intramineral fractures. (Pl.3, Fig.1). The crystals of olivine have been partially transformed to iddingsite (Pl.2, Fig.1). These fractures are the pathways along with the alteration begins in the minerals. Many intramineral cracks are still visible, and they appear as dark curved thin lineaments coated with iron oxides (staining). The more weathered crystal of plagioclase is altered to smectitic clay which is crossed by numerous irregular fractures (Pl.3, Fig. 2). A slight degradation of clay minerals particles includes the formation of a thin brownish rim of iron oxyhydroxides around each of these fragments.

Olivine has been completely replaced by bright red iddingsite. These secondary products exhibit an irregular banded pattern (PI.3, Fig. 3). Iddingsite still contains small remanents of partially and also penetrates the olivine crystal as to a peripheral and an irregular linear pattern. The large residues of Olivine cores altered to brownish iddingsite. Open transmineral fractures cross grains of Olivine have been replaced by iddingstite. The reddish brown iddingstite is highly birefringent.

Also olivine crystals have been partially altered to serpentine and the large residues of olivine cores have been altered to brownish Iddingsite. (Pl.3, Fig.3) Deposits of secondary magnetite associated with the formation of serpentine. Serpentines are present as the alteration products after olivine. It is present in the form of fibrous yellowish crystals usually along the borders and cracks of the olivine grains. Pyroxenes occur in the form of anhedral to subhedral crystals with two sets of cleavage. Pyroxenes are characterized by corroded outlines defined by fine grained iron oxides. 


\section{Plate (2)}

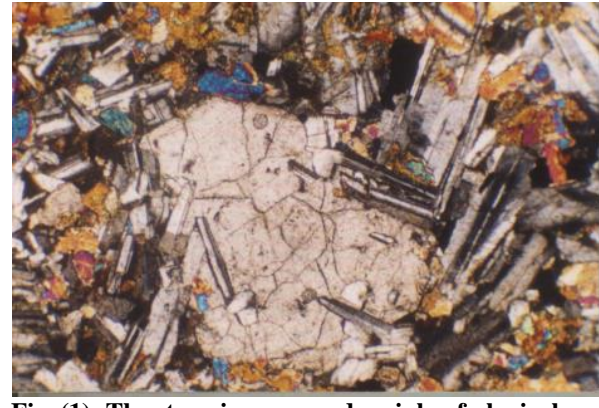

Fig. (1): The stone is composed mainly of plagioclase clinopyroxlne as essential minerals. Iron oxide occur as accessory minerals.

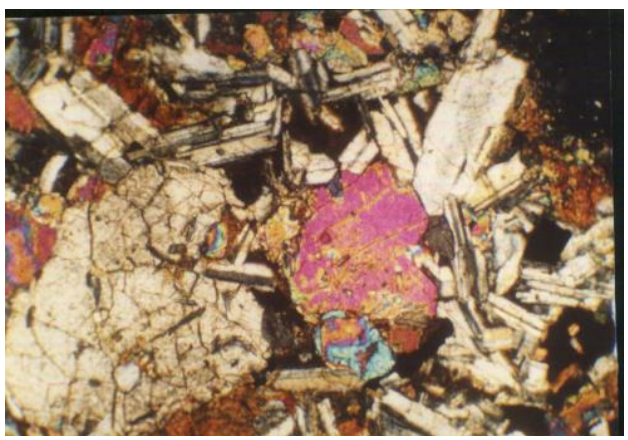

Fig. (3) :Corroded, fractured and twinned plagioclase fledspar crystals. These crystals are prismatic with "T-shape" intergrowth. The large plagioclase crystal is the middle \& vien showed as affected by deep cracking

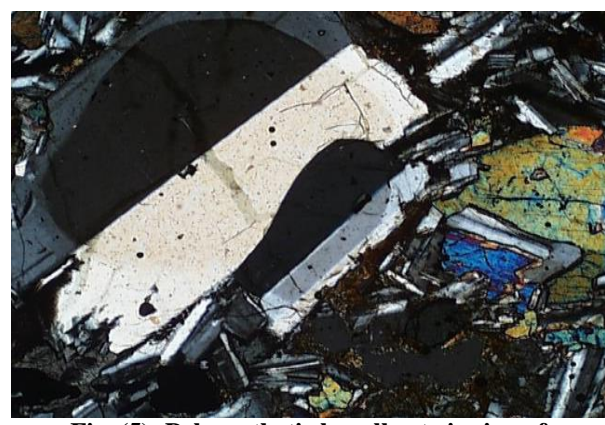

Fig. (5): Polysynthetic lamellar twinning of plagioclase phenocrestals in basalt sample. Cracks are also observed.

The weathering of pyroxene starts along the intermineral pores. The groundwater allows the pores to be widened partially by internal erosion of the newly formed secondary clay and partially to their own degradation into more iron-rich kaolinite

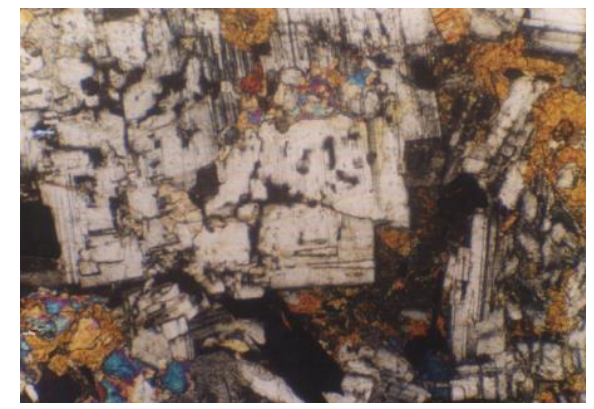

Fig. (2): Plagioclase feldspar crystal with "patchy zoning" which described as corrected core of plagioclase crystal and the outer ones are more sodic in composition. Inclusion of this sodic phase appears in the corroded core.

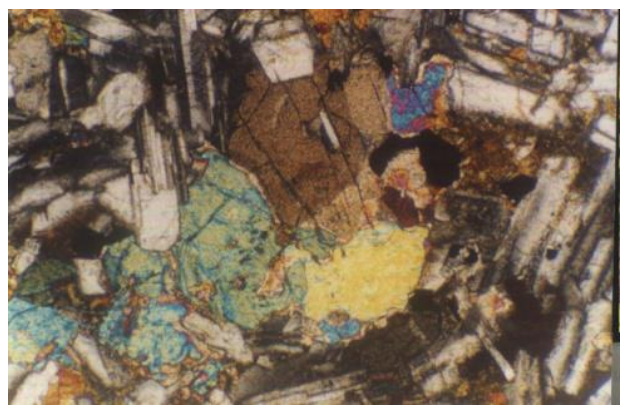

Fig. (4): highly affected and corroded phenocrystals of plagioclase and pyroxen with diagonal fracturing along the crystals and the alteration products concentrated on the rim than the core also alteration of pyroxene and olivine crystals was clearly observed

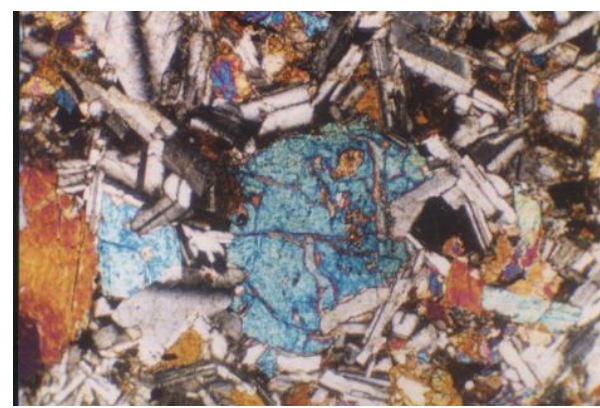

Fig. (6): Phenocrystals of olivine highly altered to irregular brownish products. With extensive network of intramineral fractures.

clay minerals in the fracture within or between the neighboring grains of pyroxenes and the opening of many interlayer pores in clay material (PI. 3, Fig. 4).

Pyroxene crystals are observed as fractured and crossed by many intramineral cracks. (PI. 3, 
Fig.5) shows a phenocrysts of pyroxene embedded in a fine groundmass of plagioclase and olivine. Clinopyroxene is pitted, and cracked altered with rugged outlines. The orientation of some cracks is strongly related to the nearly orthogonal cleavages of the mineral. The intermineral pores are completely surrounded pyroxene phenocrysts and separate them from the weathered basaltic matrix. The network of fissures is irregularly distributed and interconnected. These fissures and pores have been partially infilled with iron rich material derived from the surrounding weathered matrix and under the chemical weathering, the network of cleavages will provide the preferential pathway for the replacement of the crystals by secondary iron oxides and hydroxide chlorite which are formed as a result of the alteration of pyroxenes.

The clinopyroxene partially weathered to a smectite clay, with the development of iron oxyhdroxides from the remnants of pyroxene. All the grains are also colored by iron oxhydroxides, derived from the weathering of pyroxene remnants, which give the brownish color to the inner boundary of the smectitic secondary products. (PI. 3, Fig. 5). A crystal of clinopyroxene is intensely fractured. A set of parallel thin transmineral fissures run across several adjacent crystals of clinopyroxene. The original fissures are widened, along their walls, by weathering processes.

The wide transmineral fractures that cut the stone are infilled with a smectitic clay. The infillings seem to be formed gradually with the opening of the fractures. A part of the colorless pyroxene mineral has been transformed by randomly oriented and distributed microcrystals of green chlorite. Also the irregular grains of clinopyroxene have been replaced by reddish brown oxyhdroxides of iron (Pl.3, Fig. 6). Crystals of orthopyroxene surrounded by clinopyroxene are crossed by numerous fissures. Orthopyroxene crystals are crossed by transmineral fissures where they are separated by intermineral fissures. These provide the pathways along which the isolated grains have been partially weathered, to a yellowish secondary products. Orthopyroxene has been weathered to a very porous oxyhydroxdes of iron. Microparticles are easily loosened from the altered minerals formed at the expense of pyroxene and olivine by swelling and shrinkage, and transported along the large continuous fractures. The alteration of basalt minerals to clay minerals has produced an increase in the original volume of the stone. This increase is expressed by the extensive fracturing of the grains and the formation of many transmineral and intermineral fractures within or between the neighboring grains of pyroxenes and the opening of many interlayer pores in clay material. Thus pyroxene crystals seem fractured and crossed by many intramineral cracks.

The opaque grains of magnetite that are located along the pathway of the fissure remain undisturbed and unaltered. The magnetite and the other opaque minerals seem to be either intersectal or enclosed crystals. The weathering of opaque minerals is crossed by numerous twin planes, lamellar intergrowths and transmineral fractures. The peripheral pattern of weathering loses its regularity.

Basalts have veinlets of variable sizes. Some of which are filled with secondary minerals. Such as calcite. In some cases calcite lines the walls of the vesicles.

Vesicular structure filled with neoformed crystals of calcite is shown in (Pl.3, Fig. 2) as alteration products. 


\section{Plate (3)}
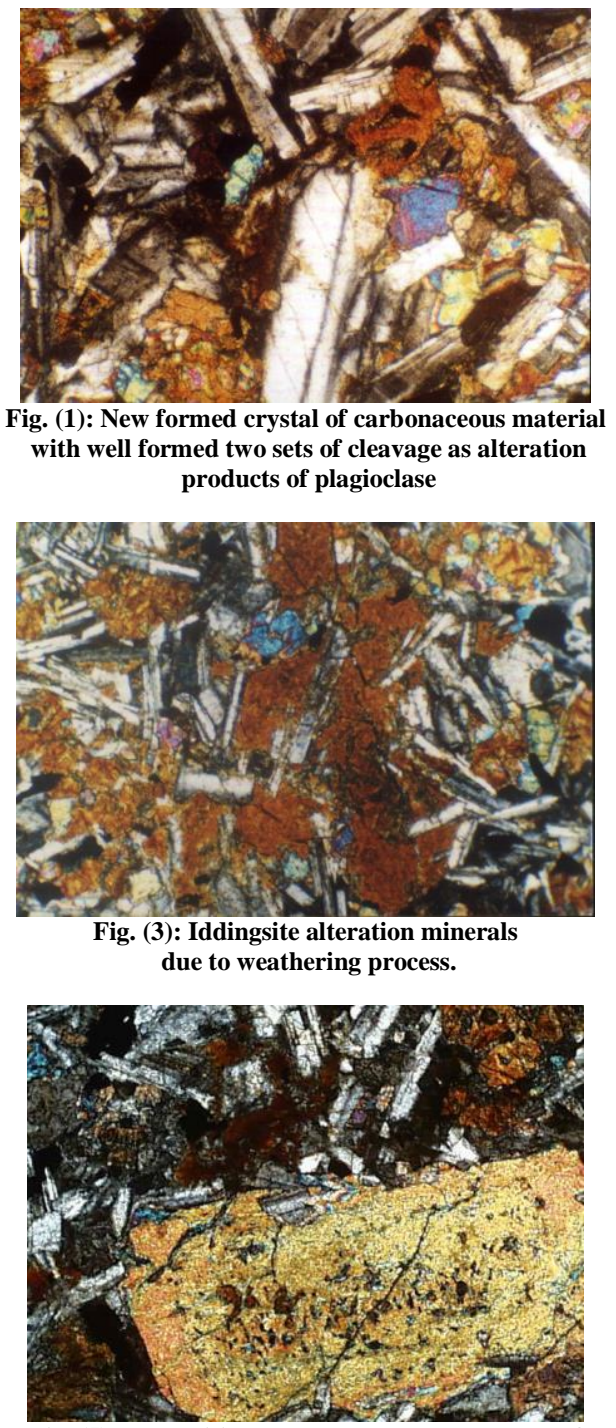

Fig. (5): Prohyritic texture, large phenocrystals of pyroxene embedded in a fine groundmass of plagioclase, pyroxene and olivine partially altered with rugged out lines.

Scanning electron microscope studies of basalt reveal a net of inter, intra and trans-granular fractures which may be taken as an index of the heavy deterioration of stone (PI. 4, Fig. 1). SEM micrographs show a long fissures inside the internal structure of the stone and show most mineral grains are loosened by the network of fissures and the opening of the mineral grains boundaries. Moreover SEM micrographs show that a network of channels and pores created in the weathered
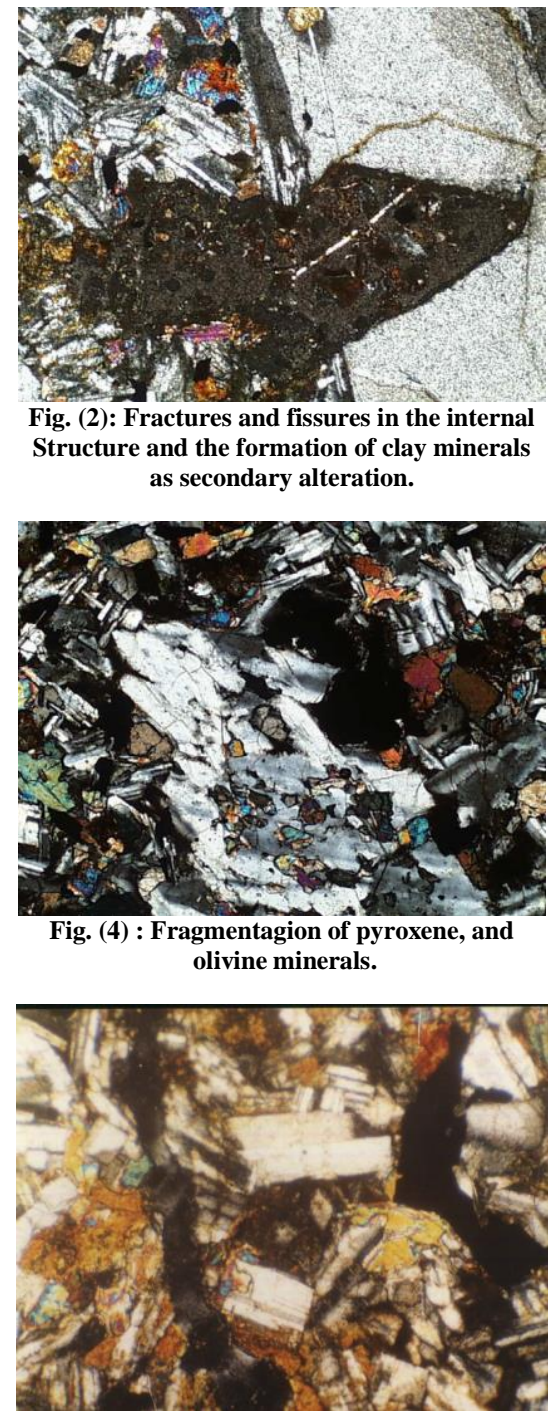

Fig. (6): Vesicular structure of basalt filled with minerals (such as iron oxides, salts).

stones and the fracturing and fissuring of the basaltic stone constituent minerals such as transmineral fissures from dislocation and of the separation of the intermineral fissures, pores and the formation of residual pores which are located either within the intramineral pores or partly developed between the newly formed secondary products and the residual fragments (Pl.4, Fig.2). Fracturing of basaltic stones is detected on all scales from megascopic to submicroscopic. Stones with 
more fracturing will have access and through flow of weathering by groundwater. Also, there is an increase in the proportion of pores, fissures and channels.(PI.4, Fig.3) SEM micrographs show that the phenocrystals minerals are fractured and the resulting fragments are separated by open transverse fractures which increase the weatherability of the minerals and consequently the fragmentation of the minerals (PI.4, Fig.4). The transmineral porosity created by the recent fracturing of the weathering stone under the influences of physical and chemical processes lead to the opening of the material by dissolution of the remnants of weatherable minerals and the internal erosion of the colloidal particles and the influence of biological origin. SEM micrographs show an open system of fissures progressively develop around residual boulders and fractures generated by internal stresses due to the hydration and swelling of some secondary clay minerals.

Plate (4)

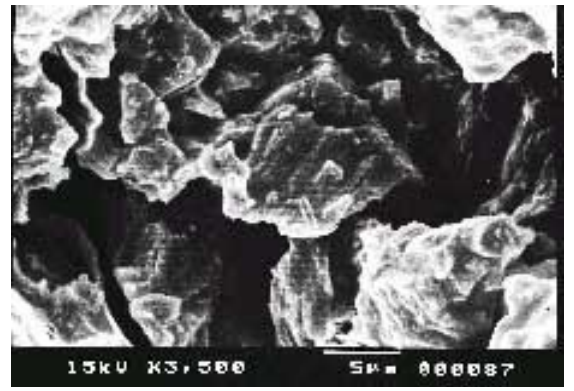

Fig. (1): SEM reveal a heavy deterioration of stone and increasing of porosity

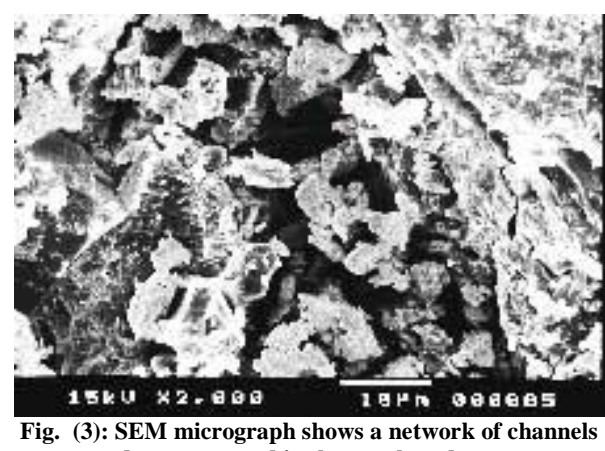
and pores created in the weathered stones.

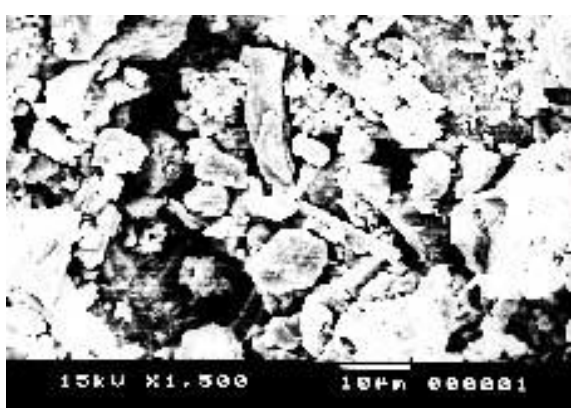

Fig. (5) :SEM shows the alteration and disintegration

of minerals

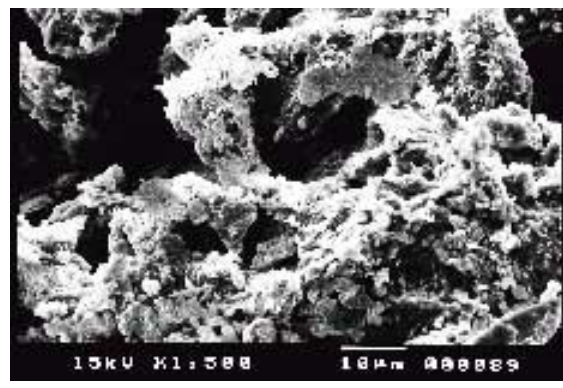

Fig. (2): SEM shows the formation of residual pores developed between the newly formed secondary products and residual fragments.

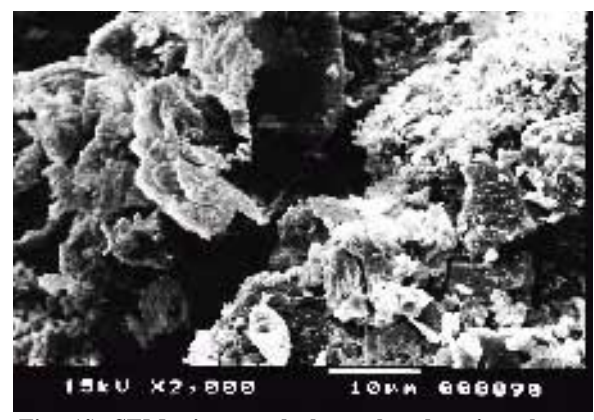

Fig. (4): SEM micrograph shows that the minerals are fractured and the resulting fragments are separated by open transverse fractures.

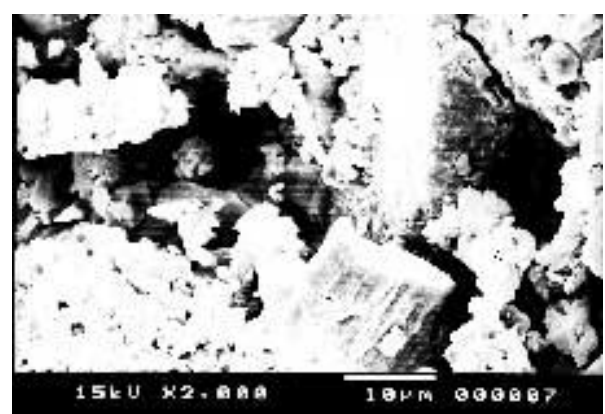

Fig. (6): SEM shows the fragmentation of the minerals and the recent fracturing of stone and the influence of biological erosion 
Also, SEM micrographs show an intermineral network of fissures results from the physical processes leads to the disaggregation of the stone by chemical dissolution processes and shows a deformation and fragmentation of the secondary minerals due to the influence of alternating conditions of humidity and dryness.

The increase of porosity is due chiefly to the interamineral porosity resulted from the replacement of a primary mineral by an aggregate of secondary minerals whose total volume does not fill all the available volume delimited by the boundaries of the original mineral, and it is related to the rate of leaching of the elements. SEM investigations show irregular, sinuous and randomly spaced alignments of alternately open and closed pores as intermineral pores. The intermineral network is interconnected and opened because it is formed and widened by peripheral dissolution, chemical weathering and mechanical fracturing.

SEM micrographs show a network of intermineral pore space which extend 5 over long distances may be preferentially exploited by microfauna. (PI.5, Fig.1) Pittings are also present on the studied samples. (Pl.5 Fig. 2) The diameters and depths of these pits vary from macroscopic to microscopic scales. Some microflara is present inside these pits associated with the activity of microorganisms. Biological factors are also responsible for the formation of irregular channels and galleries which may be partly infilled by materials of the biological origin while physical factors are mainly responsible for the opening and widening of the early formed intermineral and transmineral fractures.

Microfracturing, including both microcracks and voids, is facilitating the disintegration processes of the stone. Dissolution cavities are also detected. These cavities are either empty or partly to completely filled by salts. (PI. 5, Fig. 3) Moreover, SEM micrographs indicated numerous and open fractures cut the pre-existing volumes. It is also detected by examining the studied samples that intramineral porosity may also appear and develop by the degradation of the first -formed unstable alteroplasms. (PI.5, Fig.4). The dissolution and leaching of several constituents lead to the formations of irregular alveolar pores which may be randomly distributed. The macroporosity is restricted to the fissures, fractures and channels of higher order which cross the alterites and the empty pores existing between the microparticles of secondary products. Also, it can be enhanced as a natural impregnation of coloured materials. Detailed examination on the distribution of this pore space show that it is interparticular and generally uniform and occupy all the available space resulting from the disappearance of the primary minerals. SEM micrographs also shows the pigmentation of the crevice and interspaces between the grain boundaries of the mineral constituents. Pigmented minerals penetrate also into cracks and cleavage planes in the individual mineral grains or coat the grains as thin film. This pigmentation may be due to the degradation of the iron bearing minerals.

Mesoporosity corresponds to residual pores where distorted, opened and connected with the other system of pores and results from the development of secondary minerals that do not occupy all the available space created by weathering of the primary minerals. (Pl.5, Fig. 5) The connected pores act as channels for the soluble salts, and the movements of these salts play a great role in the deterioration of the stone. The result is powdering and flaking of the Basalt surface, in addition to carving the reliefs. It is clarified that the distribution of porous system control the different patterns of deterioration. The inhere weakness planes of the constituent minerals also affect the deterioration of the stone (Pl. 5. Fig. 6). 


\section{Plate (5)}

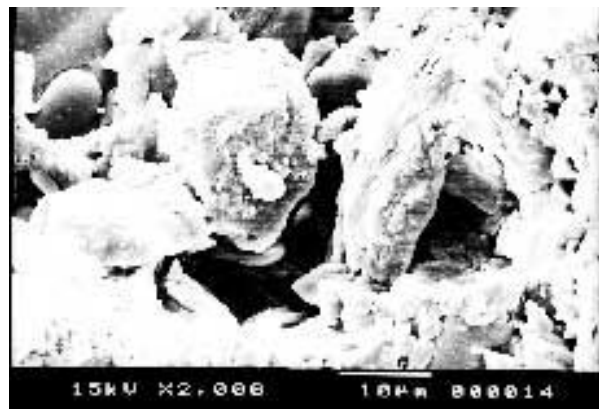

Fig. (1) :SEM shows the dislocation and the separation of the grains and the formation of residual pores.

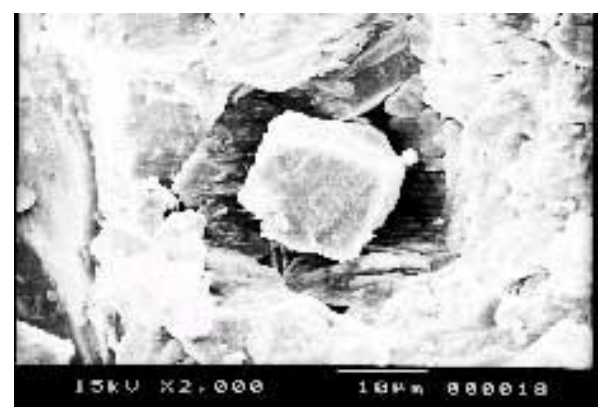

Fig. (3) : SEM shows salt crystals form wiskers filling secondary micropores and coats its texture

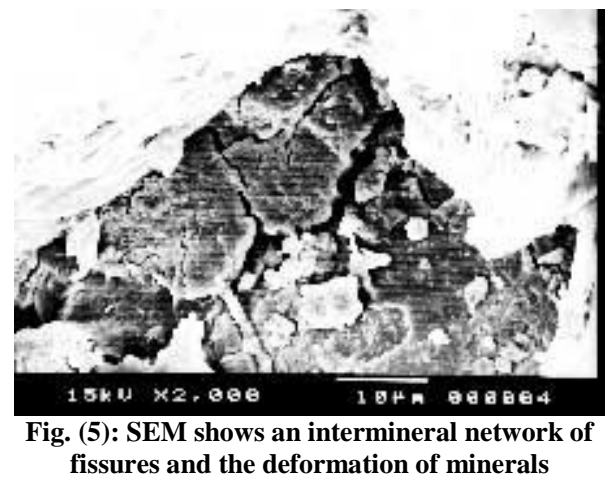

\section{$\mathrm{X}$-ray diffraction analysis :}

X-ray diffraction patterns of weathered basalt (Fig.1), proved that they consists of olivine, plagioclase, Anorthite. The relavitively more weathered samples are more rich in sheet silicate minerals i-e clays, chlorite. X-ray data (Fig.2) of weathered samples reveals the presence of montmorillonite and kalonilite. These swelling clay minerals causes stresses and weaken the consistency of the stone.

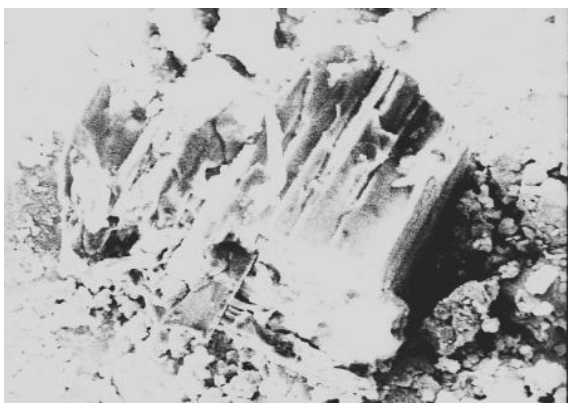

Fig. (2): SEM shows microcracks withing Basalt texture, pitting crystal, can be noted.

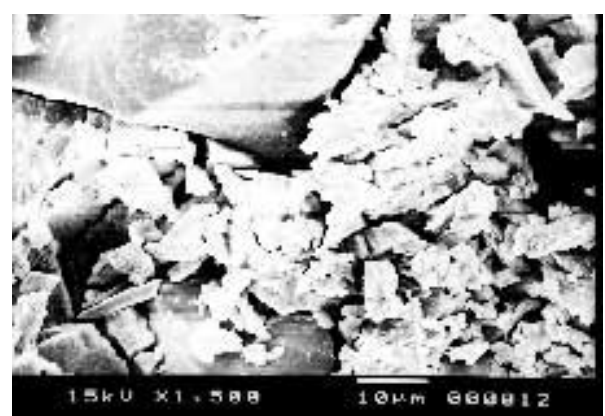

Fig. (4): SEM shows that most mineral grains are loosened from each other

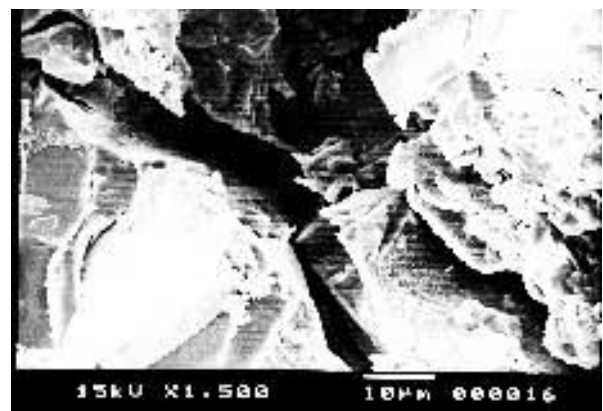

Fig. (6): SEM shows wide transmineral fractures cut the stones.

\section{Energy dispersive analysis EDX:}

Energy dispersive EDX of deleriorated samples reveals a high content of chlorine CI may be due Halite Fig. (3). EDX analysis show a loss of silica. The increase of alumina reveals the presence of clay minerals. Fig. (4) show the high $\mathrm{Fe}^{+}$from the presence of iron oxides after alteration of olivine. 


\section{Physical tests:}

The ultrasonic velocity of fresh Basalt reaches up $5000 \mathrm{~m} / \mathrm{sec}^{2}$ while the ultrasonic velocity of weathered monumental basalt reaches up 3450 $\mathrm{m} / \mathrm{sec}^{2}$ due to fissuring and cracking of basalt.

The bulk density of basalt samples is noted to improve as it $3.3 \%$ for the untreated samples to be advanced to reach up to $3.62 \%$ for Rhodorsil $224 \&$ $3.48 \%$ for Wacker $\mathrm{OH} 100 \& 3.56 \%$ for Wacker 290 \& $3.5 \%$ for sileaster A.R \& 3.5\% for Tegovakon $V$ \& 3.48\% for Baraloid B44.

The samples treated with Rhodorsil 224 show a decrease in a total porosity by $\mathbf{5 7 . 9 5 \%}$ and water absorption by $78.4 \%$. In the treatment by Wacker 290 a decrease of $48.86 \%$ of the total porosity and $50.9 \%$ of the water absorption is observed. In the Wacker $\mathrm{OH} 100$ treatment a decrease of $31.8 \%$ in a total porosity and a decrease of $27.59 \%$ of water absorption are observed. The samples treated with sileaster A.R show a decrease in a total porosity by $40.51 \%$ and a decrease in water absorption by 30.9. In the treatment by Tegovakon $\mathrm{V}$ a decrease of $30.9 \%$ of the total porosity and a decrease in water absorption by $18.4 \%$ are observed. In the paraloid B44 treatment a decrease of $26.36 \%$ in a total porosity and a decrease of $27.34 \%$ in water absorption are observed.

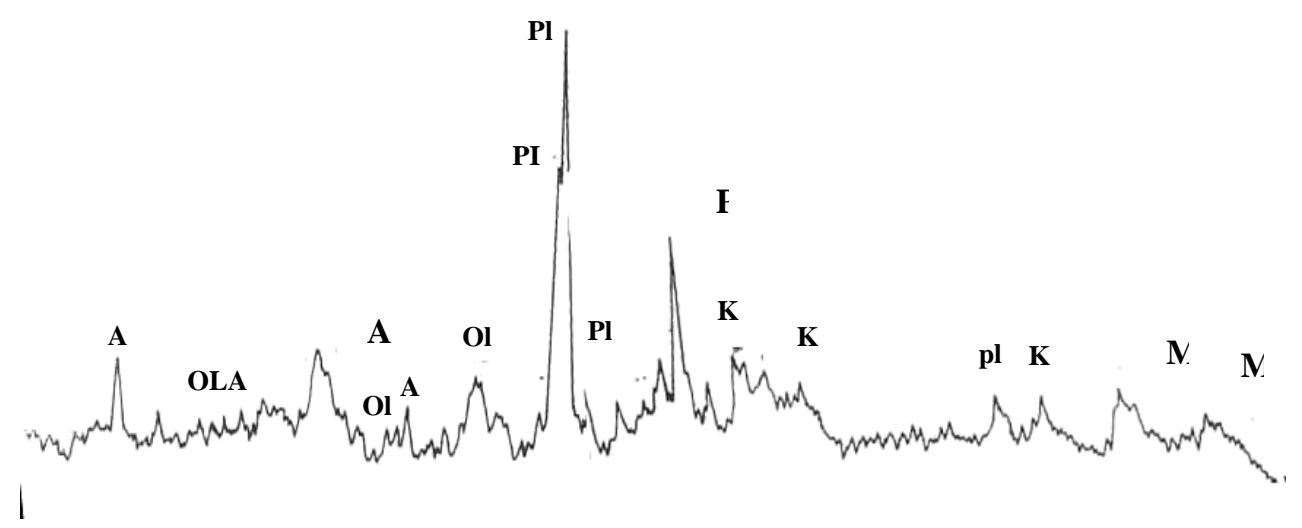

Fig. (1) : $\mathrm{x}$-ray diffraction pattern of basalt shows the prescience of clay minerals

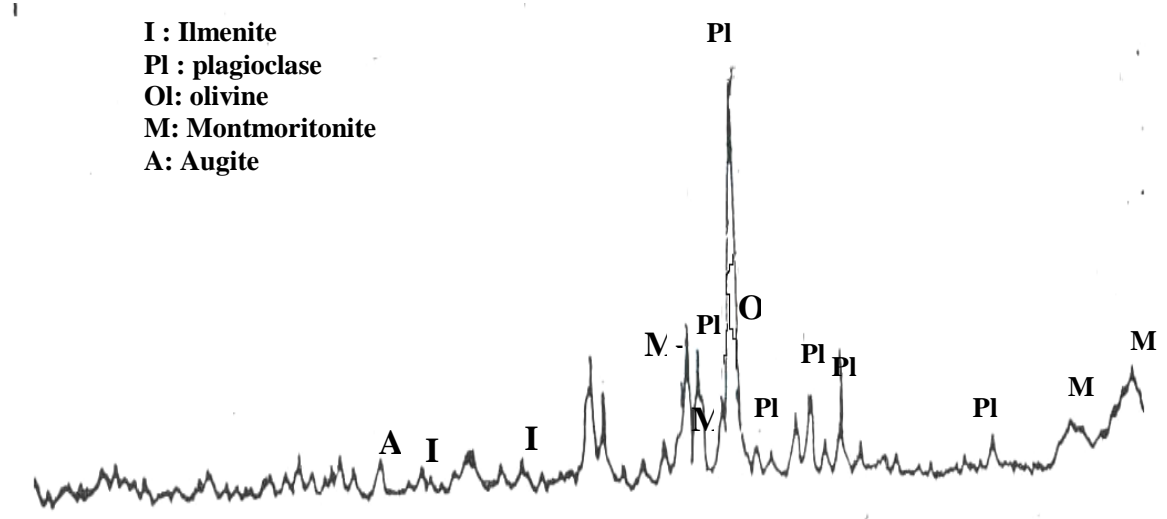

Fig. (2) : $\mathrm{X}$-ray diffraction pattern of deteriorated basalt. 
Ass. Univ. Bull. Environ. Res. Vol. 7 No. 1, March 2004

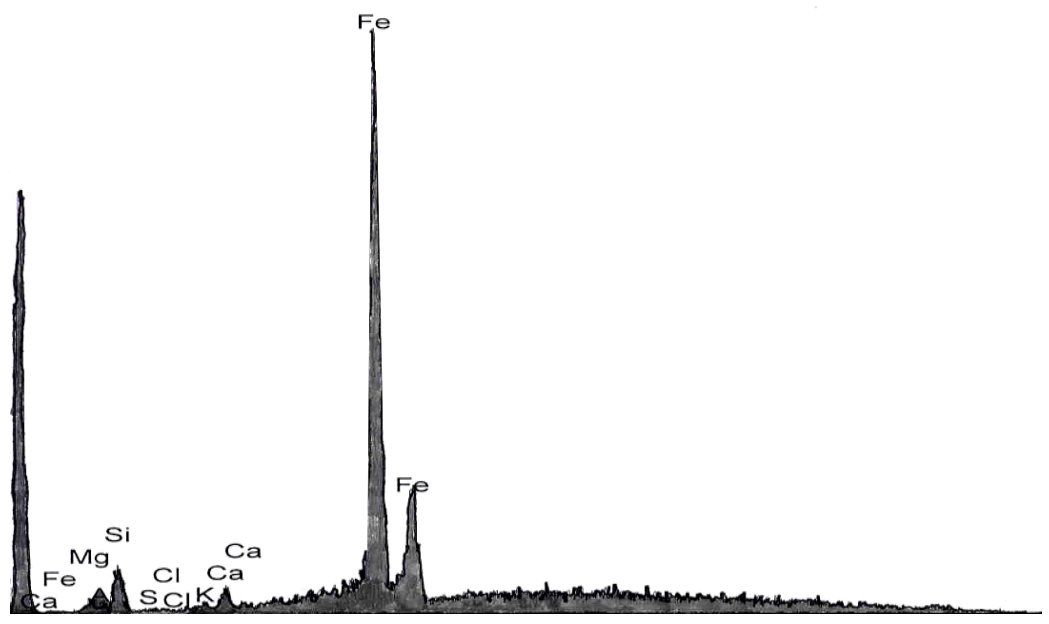

Fig. (3) : EDX shows the presence of chlorine and suluphate, in the samples.

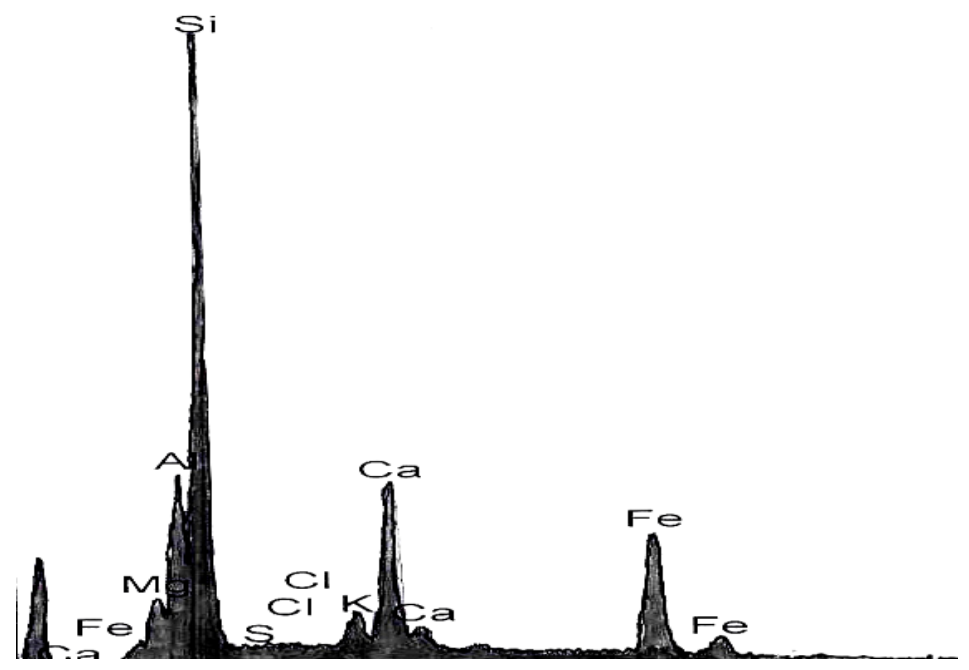

Fig. (4) : EDX shows high concentration of iron oxides and Iddingsite.

$-165-$ 
Plate (6)

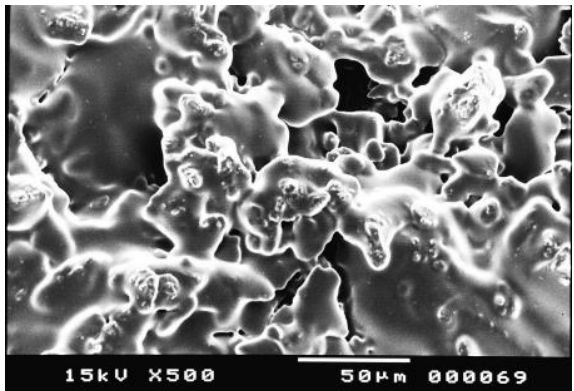

Fig. (1): SEM micrograph shows paraloid B44 covers the grains in a dense form.

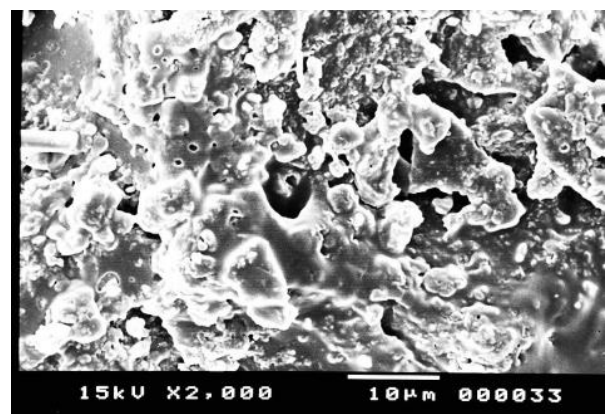

Fig. (3): SEM micrograph shows wacker 290 formed a partial distribution between the grains.

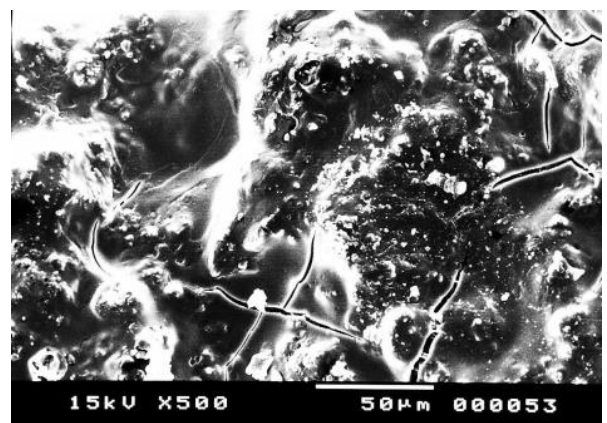

Fig. (5) SEM micrograph shows slieaster A.R covers the grains but new crack s developed in the polymer cover.

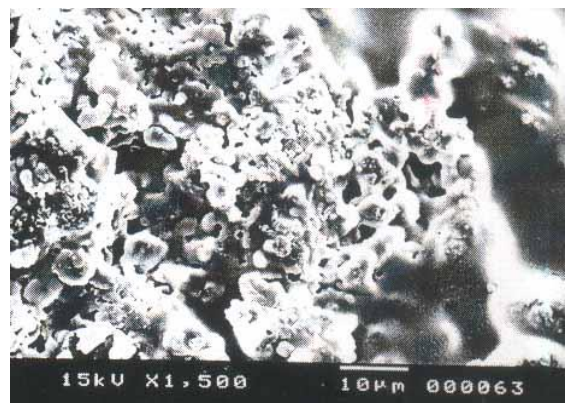

Fig. (2) : SEM micrograph shows paraloid B44 cracked and small vugs developed after artificial weathering

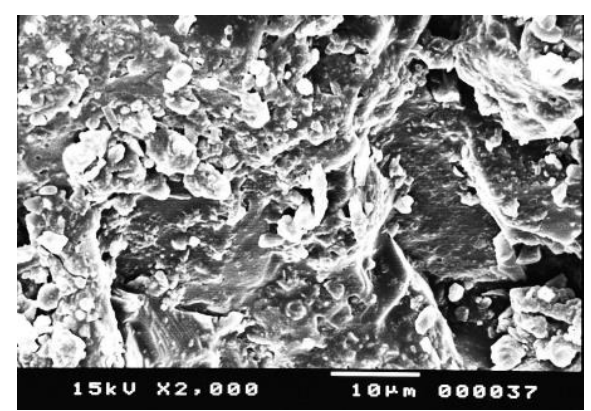

Fig. (4): SEM micrograph shows the cracking of wacker 290 after the artificial weathering.

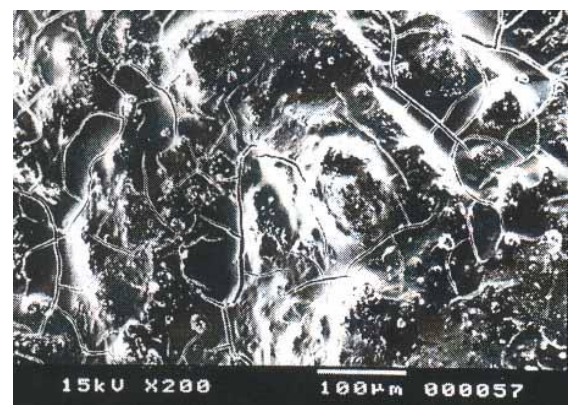

Fig. (6): SEM micrograph shows a different cracks in slieaster A.R after artificial weathering. 


\section{Plate (7)}

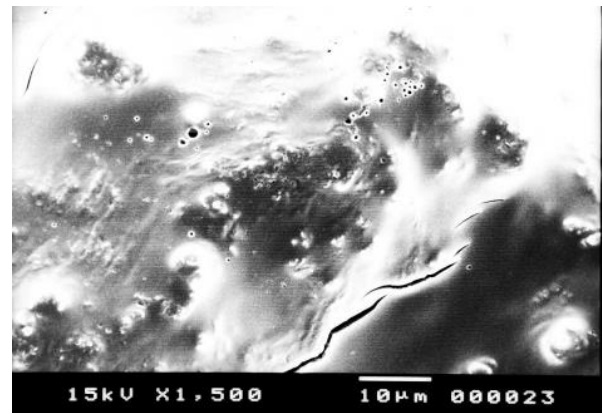

Fig. (1): SEM micrograph shows wacker OH 100 covers the stone grains in a dense form.

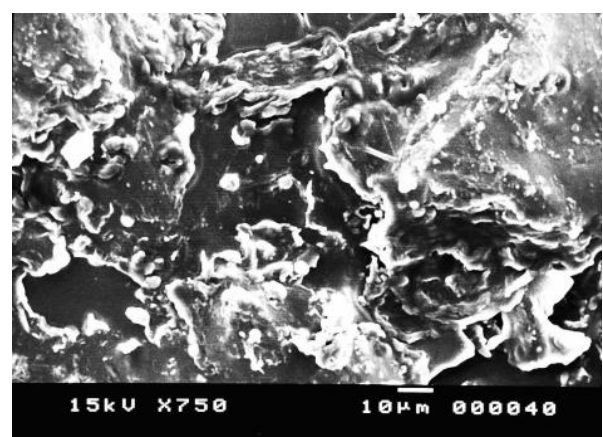

Fig. (3): SEM micrograph shows Tegovakon $V$ forms a partially film which coats the stone grains.

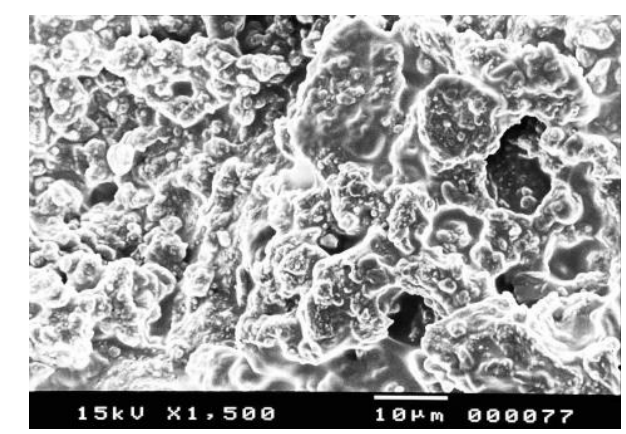

Fig. (5): SEM micrograph shows Rhordorsil 224 partially forms a thick cover distributed between the grains.

The Basaltic stones treated with six resins indicated that after their exposure to artificial weathering to loose weight ranging from $0.38 \%$ to 9.2\% with lowest weight loss for that treated with Rhodorsill 224 with $\mathbf{0 . 3 8 \%}$ (Table 1).

The treatment with Wacker 290 yielded a $19.29 \%$ of $13.33 \%$ in the percent of change of water absorption and total porosity after artifical
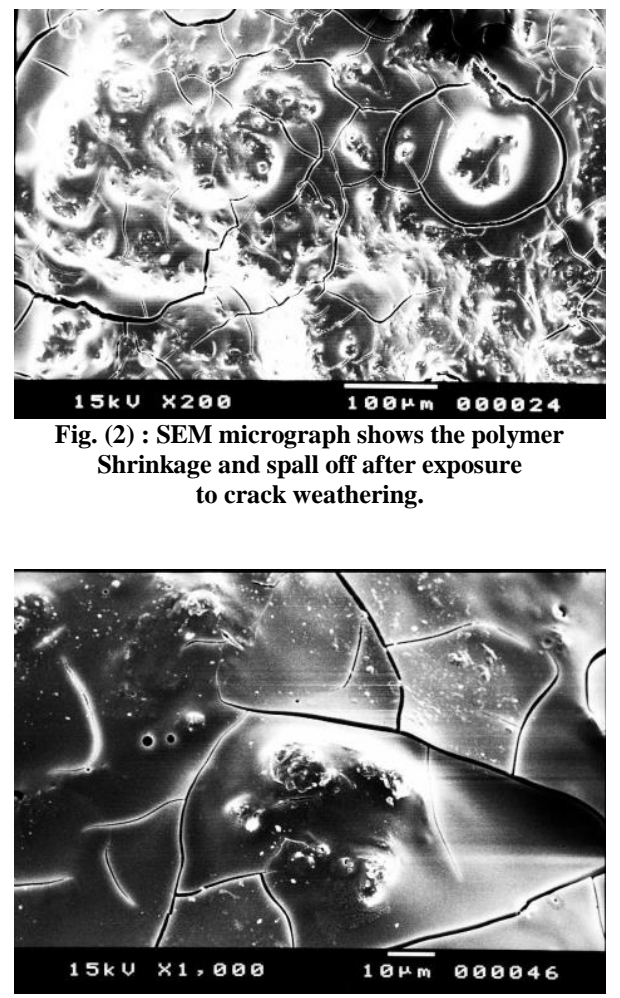

Fig. (4): SEM micrograph shows Tegovakon $V$ shrinkage and cracked after artificial weathering.

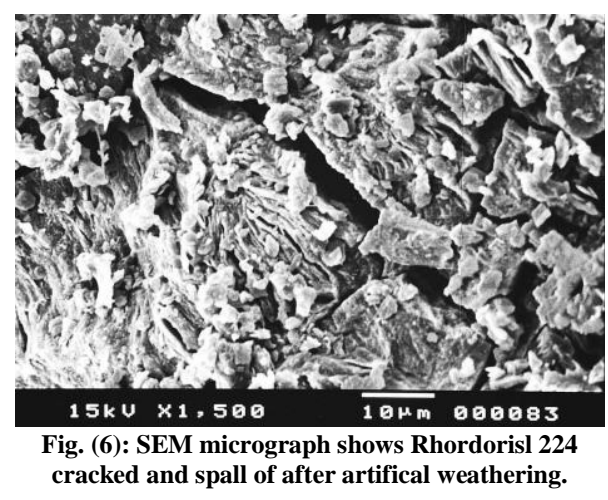

weathering Rhodorsil 224 gave $16 \%$ \& $10.8 \%$ increase in the percent of change of water absorption and total porosity. Wacker $\mathrm{OH} 100$ gave a $29.5 \% \& 30.6 \%$ in the percent of change of water absorption and total porosity after artifical weathering while Tegovaton $\mathrm{V}$ gave a $32.9 \%$ \& $32.89 \%$ in the percent of change in the total porosity and water absorption. The treatment with 
sileaster A.R yielded a $35.5 \%$ \& $32.89 \%$ in the percent of change of water absorption and total porosity. The treatment with Rhodorsil 224 A.R yielded a $42.85 \%$ \& $88.40 \%$ in the percent of change of water absorption and total porosity.

Table (1) : Shows the physical characteristics of monumental basalt before $\&$ after treatment.

\begin{tabular}{|c|c|c|c|c|c|c|c|c|c|c|c|c|c|}
\hline \multirow{4}{*}{$\begin{array}{l}\text { Bulk density } \\
\text { Water absorption } \\
\text { Porosity }\end{array}$} & \multirow{2}{*}{$\begin{array}{c}\text { Untrated } \\
3.44\end{array}$} & \multicolumn{2}{|c|}{$\begin{array}{c}\text { Rhodorisil } \\
224 \%\end{array}$} & \multicolumn{2}{|c|}{$\begin{array}{c}\text { Wacker } \\
290\end{array}$} & \multicolumn{2}{|c|}{$\begin{array}{l}\text { Wacker } \\
\text { OH100 }\end{array}$} & \multicolumn{2}{|c|}{$\begin{array}{c}\text { Sileaster } \\
\text { A.R }\end{array}$} & \multicolumn{2}{|c|}{$\begin{array}{c}\text { Tegovakon } \\
\text { V\% }\end{array}$} & \multicolumn{2}{|c|}{$\begin{array}{c}\text { Paraloid } \\
\text { B44 }\end{array}$} \\
\hline & & 3.62 & 5.3 & 3.6 & 4.65 & 3.56 & 3.48 & 3.50 & 1.74 & 3.5 & 2.90 & 3.48 & 1.16 \\
\hline & 1.16 & 0.25 & 78.4 & 0.57 & 50.9 & 0.61 & 47.4 & 0.69 & 40.51 & 0.73 & 37.1 & 0.84 & 27.59 \\
\hline & 0.88 & 0.37 & 57.95 & 0.45 & 48.86 & 0.75 & 31.8 & 0.74 & 17.04 & 0.76 & 30.9 & 0.69 & 26.36 \\
\hline
\end{tabular}

Table (2) : Shows the physical characteristics of monumental basalt after artificial weathering.

\begin{tabular}{|c|c|c|c|c|c|c|c|c|c|c|c|c|c|c|c|c|c|c|}
\hline & \multicolumn{3}{|c|}{ Rhodorsil 224} & \multicolumn{3}{|c|}{ Wacker 290} & \multicolumn{3}{|c|}{ Wacker OH100 } & \multicolumn{3}{|c|}{ Tegovakon V } & \multicolumn{3}{|c|}{ Sileaster A.R } & \multicolumn{3}{|c|}{ Paraloid B44 } \\
\hline D\% & 3.62 & 3.25 & 3.5 & 3.6 & 3.5 & 2.77 & 3.56 & 3.4 & 4.49 & 3.51 & 3.21 & 8.54 & 3.50 & 3.10 & 42.02 & 3.48 & 2.91 & 16.37 \\
\hline W\% & 0.25 & 0.29 & 16 & 0.59 & 0.68 & 19.29 & 0.61 & 0.79 & 29.5 & 0.73 & 0.97 & 32.9 & 0.69 & 0.97 & 35.52 & 0.84 & 1.2 & 42.85 \\
\hline
\end{tabular}

Table (3): Shows the weight loss of treated monumental basalt after salt weathering.

\begin{tabular}{||c|c|c|c|c|c|}
\hline Rhodorsil 224 & Wacker 290 & Wacker OH100 & Tegovkon V & Sileaster A.R & Paraloid B44 \\
\hline 0.38 & 0.61 & 0.64 & 0.67 & 8.58 & 9.20 \\
\hline
\end{tabular}




\section{DISCUSSION:}

Basalt is a basic volcanic igneous rock composed of mafic minerals in particular plagioclase Olivine and Pyroxene. It is a crystalline (Cryptocrystalline) rock and some of their minerals are easily weathered as they have been formed at high temperatures and they have sets of cleavage either perpendicular on each other or at obtuse angles.

Basalt is affected by several types of deterioration namely granular disintegration, plats, Flakes, efflorescences and biological colonization. The influence of environmental factors has played an important role in the deterioration process of Basalt, particularly due to the biodeterioration agents.

Continuous disintegration of basalt have been observed. Cracks are produced in the body of the stones and small pieces have been observed. Cracks are produced in the body of the stones and small pieces have been exfoliated from the surfaces. The deterioration of basaltic monuments continue by new cracks in the stones and exfoliations from the surfaces.

Insolation weathering dominates in Egypt, as the climatic conditions (Temp. is high to very high and humidity is low in general) are suitable for that process. As the temperature variation is very rapid and variable between day and night as well as from season to the other, then these minerals are weathered along its cleavage system by expansion and contractions of these minerals. The plagioclase group recorded in the thin sections and SEM images clarify that minerals alteration is easily happening. The disorientation noted in the thin sections examined the collected basaltic samples.

The large plagioclase crystals are shown to be affected by deep cracking (PI.1 Fig.2). The weathering starts in the plagioclase crystals in the peripheral parts of the crystals. The clay minerals are formed as a secondary clay products after plagioclase along the network of intergranular micropores. The weathering of twinned crystals of plagioclase have begun along intramineral cracks (PI.2 Fig.3) in which highly altered and corroded phenocrysts of plagioclase with diagonal fracturing along the crystals and several fissures are more recently formed. Plagioclase is progressively replaced along numerous fissures. The transformation of the plagioclase into secondary clay minerals which is concentrated on the rim of the core with an appreciable increase in volume has promoted the opening of many intermineral fissures and fractures (PI.2, Fig.3). The intermineral 
fissures and intramineral cracks are filled by brown iron oxyhdroxides (P15., Fig.5). plagioclase is also altered by yellowish color which is due to impregnation with iron-rich compounds.

Olivine is one of the main minerals composing. Basaltic rocks is easily weathered as noted in the thin sections and scanning electron photomicrographs. It exhibits an irregular variable colours in crossed Nicoles. Lots of intramineral cleavages are pathways through which weathering takes place.

The non preferred orientation of the laths of plagioclase and enables moisture, salts, other chemical and weathering processes to take place in between these laths. The mineralogical investigation for this weathering indicated that olivine has been altered to iddingsite that still contain small relies of olivine as an original mineral of this newly formed weathering product. The variation of Basaltic black colour also indicated its weathering.

The olivine is largely replaced by reddish brown iddingsite whose formation is mainly started along the newly formed Smectite. Iddingsite which has reddish to yellowish brown color partially pseudomophs after olivine crystals. Iddingsite is not a single mineral and consists from a mixture of iron oxide and hydroxide associated with chlorite (Eggleton, 1984). Iddingsite after olivine which is converted to goethite by the leaching of its silicate components. Iron hydroxide (goethite) is formed along the fissures and is replaced by anhydrous iron oxides (hematite) preferentially formed in the plasma rich shells.

Most pyroxene crystals in samples have been separated by a regular network of intermineral fissures. These provide the pathways along which the isolated grains have been partially weathered.

SEM micrographs show the formation of voids, and mciroveins in their structure due to the influence of the weathering process on the stone. Most residual voids are formed within the peripheral residued voids surrounding the secondary products and results from the opening of existing intermineral void. Fissures and pores appear in the examined samples and develop within the weathering stone and result from fracturing and fissuring of the stone and from the dislocation and separation of the intermineral fissures and pores, irregular networks of interconnected fractures in weathered Basalt which produce deformation of the stone and induce irregular fracturing of its mineral constituents. They also found in the opening of fissures and fractures that traverse the stone. These networks of fissures and fractures consisted of interconnected fractures can easily be opened and coated by secondary deposits. They also found as irregular shapes which observed in the altered and fractured minerals and a highly porous and its internal pore-space is directly connected with the fissures related to the altered minerals and filled with secondary materials. Moreover, numerous discordant intermineral fractures are observed and the development of intramineral porosity in the stone which is exclusively due to the processes of weathering.

Microporosity and mesoporosity are distinguished according to the size of the pores connected to the secondary material which may also result from later irregular degradation and incomplete dissolution of mineral constituents under the influence of later swelling of the secondary clay by hydration.

To preserve the monuments in the conditions of arid climate as in Egypt and based on the detailed study of rock petrography, lowering depth to sub surface water with its dissolved salts \& combined with climate conditions.

Removal of salts from stone surface are preffered to keep the Basalt free from the impact of salt crystallization and salt thermal expansion in the arid climate of Egypt. Rodorosil 224 and Wacker 290 improve the physical characteristics of monumental basalt. 


\section{REFERENCES:}

Arnold, A., Zehnder, K., 1990: Salt weathering on monuments Analytical Methodologies of the investigation of damaged stones. Pavia.

Cancer, E. and Turkmenogha, A., 1985: Deterioration of basalts from a Himite archaeological site, Karatepe, Turkey. Pp $411-420,5^{\text {th }}$ international congress on the conservation of stone, laursanne, 25-27 September.

Eggleton, R., 1984: Formation of iddingsite rims on olivine: A transmission electron microscopy study. Clays and clay minerals; vol.33. pp111.

Grissom, C., 1990: The deterioration and treatment of volcanic stone a Review of the literature Lavas and Volcans, proceedings of the international meeting. Easter island Chile 333.

Harrell, J. and Bown, T, 1995: An old kingdom basalt quarry at widian el-Faras and the quarry road to late Moeris in Fayoum. Egypt. JARCE. 32-71-91.

Heikel, M., Hassan, M. and El Sheshtawi, Y, 1983: The Cenozoic basalt of Gabel Qatarni, western desert Egypt as an example of continental theoleitic basalt AGSE 13. 193209.

Helmi, F., 1990: Lavas and Volcanic Tuffs: Proceeding of the international meeting. Easter island Chile. 25-31 October pp 53-63.

Hoffmeier, J., 1993: The use of basalt in floors of old kingdom pyramid temples, 30 pp 117-23.

Klemm, R. and Klemm, D. 1993: Steine und Steinbrich in Alten- Agypten- Berlin Springer Verlag.

Lucas, A., 1945: Ancient Egyptian Materials and Industries, London, Edward, Arnold $3^{\text {rd }}$ edition.

Skiotis, D., Beloyannis N. and Kirkitsos, ph. 1992: Application of Ion chromatography in studying the deterioration of lavas: Application at the temple of Messa in Mytilene, seventh international symposium on the Deterioration and conservation of stone, Lisbone.

Turkmenoglu, A., Gokturk, E. and Caner, E., 1991: The Deterioration of Tuffs from the cappadocia Refion of Turkey, Archaeometry, vol. 33 pp 231-338. 